\title{
Erratum to: Standardizing effect size from linear regression models with log- transformed variables for meta-analysis
}

\author{
Miguel Rodríguez-Barranco ${ }^{1,2,3^{*}}$, Aurelio Tobías ${ }^{4}$, Daniel Redondo ${ }^{1,2,3}$, Elena Molina-Portillo 1,2,3 \\ and María José Sánchez ${ }^{1,2,3}$
}

\section{Erratum}

Since the publication of our article [1], it has come to our attention that the legend to Fig. 1 did not acknowledge that this figure had been adapted from a published source. The legend to Fig. 1 should read as follows:

Relationship between $\mathrm{X}$ and $\mathrm{Y}$ changes in a linear model with logarithmic transformations. Adapted with permission from eFigure 1 in Barrera-Gómez J and Basagaña X, Models with Transformed Variables: Interpretation and Software. Epidemiology. 2015; 26 (2): e16-17, http:// journals.lww.com/epidem/Fulltext/2015/03000/Models_ with_Transformed_Variables__Interpretation.27.aspx, copyright (c) 2015 Wolters Kluwer Health Inc. [3].”

\begin{abstract}
Author details
${ }^{1}$ Andalusian School of Public Health (EASP), Campus Universitario de Cartuja, c/Cuesta del Observatorio 4, 18080 Granada, Spain. ${ }^{2}$ Instituto de Investigación Biosanitaria ibs.GRANADA, University Hospitals of Granada/ University of Granada, Granada, Spain. ${ }^{3}$ CIBERESP, Madrid, Spain. ${ }^{4}$ Institute of Environmental Assessment and Water Research (IDAEA), Spanish Council for Scientific Research (CSIC), Barcelona, Spain.
\end{abstract}

Received: 7 June 2017 Accepted: 7 June 2017

Published online: 19 June 2017

\section{Reference}

1. Rodríguez-Barranco M, Tobías A, Redondo D, Molina-Portillo E, José Sánchez M. Standardizing effect size from linear regression models with log-transformed variables for meta-analysis. BMC Med Res Methodol. 2017;17:44.

\footnotetext{
* Correspondence: miguel.rodriguez.barranco.easp@juntadeandalucia.es ${ }^{1}$ Andalusian School of Public Health (EASP), Campus Universitario de Cartuja, c/Cuesta del Observatorio 4, 18080 Granada, Spain ${ }^{2}$ Instituto de Investigación Biosanitaria ibs.GRANADA, University Hospitals of Granada/ University of Granada, Granada, Spain
} 